\title{
IDENTIFICATION OF DROUGHT EXTENT USING NVSWI AND VHI IN IAŞI COUNTY AREA, ROMANIA
}

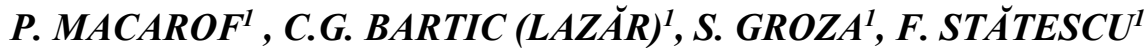

\begin{abstract}
Identification of drought extent using NVSWI and VHI in Iaşi county area, Romania. Drought is a stochastic natural phenomenon that appears from considerable lacking in precipitation. Among natural hazards, drought is known to provoke extensive damage and affects a important number of people. Techniques for observing agricultural drought from R.S. are indirect. These depend on using images based parameters to exemplifed soil moisture condition when the soil is often obscured by a vegetation cover. The procedure are mainly based on determing vegetation health or greenness using VI, often in combination with canopy temperature anomalies using thermal infrared wavebands. In this study were used remote sensing images from the Landsat 8 OLI, taken in may and june 2017. The study area was the county of Iasi. To evaluate drought in this study, for Iasi county, Normalized Vegetation Supply Water Index (NVSWI) and Vegetation Health Index (VHI), were used. VSWI is derived from The Vegetation Supply Water Index (VSWI). This index was developed to combine the NDVI and the land surface temperature (LST) to detect the moisture condition. VHI was developed through a combination of Vegetation Condition Index (VCI), one of the important vegetation indicators when monitoring weather-related variations, such as droughts, and Temperature Condition Index (TCI), which reflects the stress of temperature, that both indicies can be successfully used to determine the spatiotemporal extent of agricultural drought. After applying NVSWI to determine the degree of drought we noticed that for the satellite image of May prevailed "slight drought" and for june "normal". Second index, VHI indicate that in both months, may and june, is "no drought". It can be concluded that VHI is a very good indicator for studing extreme drought and NVSWI offer information about areas "normal" and "wet".
\end{abstract}

Keywords: Drought, Remote Sensing; Landsat 8, NVSWI, VHI.

\section{INTRODUCTION}

Extreme climatic episodes are predicted to growth in frequency and magnitude (Min et al., 2011) and are anticipated to have strong ecological implications (Jentsch et al. 2007; Knapp et al. 2008; Smith 2011; Reichstein et al. 2013).

Drought is a stochastic natural phenomenon that appears from considerable lacking in precipitation. Among natural hazards, drought is known to provoke extensive damage and affects a important number of people (Wilhite, 1993). As a climatic anomaly originating from a period of usually low precipitation, drought

\footnotetext{
1 „Gheorghe Asachi” Technical University of Iasi, Faculty of Hydrotechnical Engineering, Geodesy and Environmental Engineering, 700050, Iasi, Romania, e-mail: macarofpaul@yahoo.com bartic.georgiana91@gmail.com stef_groza@yahoo.com fstatescu@hidro.tuiasi.ro
} 
can occur in every part of the Earth's surface, even in humid regions. This phenomenon can disrupt economical and ecological systems, leading to population displacement. Moreover, sustained drought also favors desertification, according to Hirche, and land degradation, which are especially harmful for vulnerable landscapes bordering arid and semiarid areas (Pandey et al. 2013). This phenomenon is a relative, rather than absolute, condition that should be described for each region. Each drought differs in duration, intensity and spatial extent (Knutson et al., 1998). Wilhite reported, in 2000, that the onset and end, as well as severity are often hard to determine. Drought ranked as the principal among all natural hazards (Bryant, 1991). Drought is not only limit to arid and semi-arid regions but often visits potentially good rainfall zones. There is no universally acceptable and applicable definition for drought as yet. Many attempts to define drought have led to numerous definitions of the term (Nagarajan, 2003). In 2008, UNDP, defines drought as the naturally phenomenon happening that exists when precipitation has been meaningfully below normal recorded levels causing serious hydrological disequilibrium that adversely affect land resources production systems. Therefore, drought is the most costly disaster that can affect natural habitats, ecosystems, agricultural systems, and urban water supplies (Heim et al., Zhang et al. 2013). As a result, many techniques for monitoring drought conditions have been developed.

Techniques for observing agricultural drought from R.S. are indirect. These depend on using images based parameters to exemplifed soil moisture condition when the soil is often obscured by a vegetation cover. The procedure are mainly based on determing vegetation health or greenness using VI , often in combination with canopy temperature anomalies using thermal infrared wavebands. Have been developed and applied, a few remote-sensed drought indices, which including duration, spatial extent, intensity, and severity. One of these, the NDVI has been one of most usually used approaches to drought episode monitoring and as a probe for vegetation health. Combining vegetation index and temperature offer the possibility to improve the approach. A mix of LST and NDVI provides strong correlation and offers useful information to describe the agricultural drought as an early warning system.In this study NVSWI and VHI were used to evaluated drought of Iasi county.

\section{MATERIAL AND METHODS}

\subsection{Study area}

Iaşi county is considered as study area in this research. Study Area is geographically situated on latitude $46^{\circ} 48^{\prime} \mathrm{N}$ to $47^{\circ} 35^{\prime} \mathrm{N}$ and longitude $26^{\circ} 29^{\prime} \mathrm{E}$ to $28^{\circ} 07^{\prime} \mathrm{E}$. Neighborings of Iaşi county are Botosani to the north, Neamt to the west, Vaslui to the south and Republic of Moldova to the east. Iaşi county is situated in easten of Romania and it has an area of $5.476 \mathrm{~km}^{2}$. 


\subsection{Data resources}

Landsat 8 measures different ranges of frequencies along the electromagnetic spectrum - a color, although not necessarily a color visible to the human eye. Each range is called a band. Landsat 8 has 11 bands and the tenth and eleventh band are in the thermal infrared (TIR). These bands see heat. Instead of measuring the temperature of the air, such as weather stations do, it report on the ground itself, which is often hotter (NASA Landsat Science).

Landsat data was offered free by USGS and was taken on May $4^{\text {th }}$ and june $5^{\text {th }} 2017$.

\subsection{Data processing}

\subsubsection{Image preprocessing}

Preprocessing of Landsat-8 OLI images stage represent that operations that prepare images for subsequent analysis that attempts to compensate/correct for systematic errors. The images are subjected to several corrections like radiometric and atmospheric. In order to be used by some image processing aplication, the $90 \mathrm{~m}$ resolution TIR bands were resampled to "fit" to 30m spatial. Resampling is used to "keep" the original pixel values in the resampled images nearest neighbor (miningeology.blogspot).

Radiometric correction is done to decrease/correct errors in the digital numbers (DN) of images. This process improves quality of remote sensed data. The process of eliminating the effects of the atmosphere to obtain surface reflectance values represents the atmospheric correction. Atmospheric correction can significantly enhance the interpretability and usage of images. Perfectly for this process would be to have knowledge about the aerosol properties and the atmospheric conditions at the time the remote sensing data was acquired (miningeology.blogspot).

\subsubsection{Normalized Difference Vegetation Index}

NDVI, according to Rouse, is a numerical indicator that uses the visible (Vis) and near-infrared (NIR) bands of the electromagnetic spectrum, and is adopted to analyze remote sensing measurements and assess whether the aim being observed contains live green vegetation or not (John Rouse, 1974). The NDVI algorithm subtracts the red reflectance values from the near-infrared (NIR) and divides it by the sum of them.

$$
\mathrm{NDVI}=\frac{(N I R-R E D)}{(N I R+R E D)}
$$

\subsubsection{Land surface temperature (LST)}

To estimate the LST from thermal infrared (TIR) band data of Landsat- 8 OLI, DN of sensors were transformed to spectral radiance using equation (Barsi et al. 2014).

$$
\mathrm{Ll}=\mathrm{ML} \times \mathrm{Qcal}+\mathrm{AL}-\mathrm{Qi}
$$


Where:

- $\quad M L=$ the band-specific multiplicative rescaling factor

- $\quad Q$ cal $=$ the Band 10/11 image

- $A L=$ the band-specific additive rescaling factor

- $\quad O i=$ the correction for Band 10/11

Spectral radiance is converted to brightness temperature by assuming the earth of surface is a black body (Chander et al, 2009; Coll et al, 2010):

$$
\mathrm{Tb}=\frac{K_{2}}{\ln \left(\left(\frac{K_{1}}{L \lambda}\right)+1\right)}-273.15
$$

Where:

- $\quad \mathrm{Tb}=$ the brightness temperature

- $\quad \mathrm{L} \lambda=$ the cell value as radiance

- $\quad \mathrm{K} 1$ and $\mathrm{K} 2$ = Calibration constant of Landsat8 calibration

There are algorithms applied to transfer BT for LST:

$\mathrm{LST}=\mathrm{BT} /\left[1+\left(\lambda^{*} \mathrm{E} / \rho\right) * \ln (\mathrm{LSE})\right]$

Whereas, BT=Brightness Temperature (4) (Kevin) $\lambda$ is the band wavelength $(\mu \mathrm{m}), \rho=14380$; LSE $=$ Land Surface Emissivity.

NDVI was used to extract Land Surface Emissivity (LSE), which is an adjustable parameter in correcting Land Surface Temperature in the next step. Values of LSE were calculated based on the proportion of vegetation (JiménezMuñoz et al. 2014).

$\mathrm{LSE}=0.004 \mathrm{PV}+0.986$

Whereas, $\mathrm{Pv}$ is the proportion of vegetation, based on a normalized NDVI value of each pixel.

$$
\mathrm{PV}=\left(\frac{N D V I-N D V I_{\text {min }}}{N D V I_{\max }-N D V I_{\min }}\right)^{2}
$$

\subsubsection{Normalized Vegetation Supply Water Index (NVSWI)}

VSWI combines NDVI with the thermal image-based parameter LST and is regularly used to its simplicity and ability to illustrate 2 potential characteristics of vegetation stress in 1 index, but suffer from the misfit in time scales, since vegetation greenness is pretty stable in the short to medium period but temperature oscillate diurnally, and according to weather conditions as well as aspect, slope and terrain properties. VSWI is also characteristic to the land cover (LC) type and measurement time of the images scene, and can not be used as an perfect measure of drought severity. So, attempts to normalize the VSWI have contextualized the index within a defined period of available records.

$$
\mathrm{VSWI}=\frac{N D V I}{L S T}
$$




$$
\mathrm{NVSWI}=\frac{\left(N S W I-V S W I_{\text {min }}\right)}{\left(V S W I_{\text {max }}-V S W I_{\text {min }}\right)} \times 100
$$

NVSWI range from 0 (driest) to 100 (wet) with next five drought classes: severe dry (0-20), moderate drought (20-40), slight drought (40-60), normal (60$80)$, wet (80-100).

\subsubsection{Vegetation Health Index (VHI), Vegetation Condition Index (VCI)} and Temperature Condition Index (TCI)

The VCI is defined as follows:

$$
\mathrm{VCI}=100 *\left(\mathrm{NDVI}-\mathrm{NDVI}_{\min }\right) /\left(\mathrm{NDVI}_{\max }-\mathrm{NDVI}_{\min }\right)
$$

where $\mathrm{NDVI}_{\max }$ and $\mathrm{NDVI}_{\min }$ represent absolute maximum and minimum values. The VCI is used as one of the most important vegetation indicators when monitoring weather related variations, like drought. On the condition of "exaggerated" soil wetness or cloudiness, the NDVI is improper and the VCI has low values which can be interpreted wrongfully as a drought event. To differentiate droughts from excessive soil wetness or cloudiness, was developed VHI, a combination of VCI and TCI (Kogan, 1995; Kogan et al., 2011):

$$
\begin{aligned}
& \mathrm{TCI}=100 *\left(\mathrm{LST}_{\max }-\mathrm{LST}\right) /\left(\mathrm{LST}_{\max }-\mathrm{LST}_{\min }\right) \\
& \mathrm{VHI}=\mathrm{a} * \mathrm{VCI}+(1-\mathrm{a}) * \mathrm{TCI}
\end{aligned}
$$

where the TCI reflects the stress of temperature, a is a coefficient to quantify the relative contributions of moisture and temperature to the vegetation health; $\mathrm{LST}_{\max }$ and $\mathrm{LST}_{\min }$ represent the absolute maximum and minimum. Since the contributions of moisture and temperature to vegetation health are unknown for a specific location at some periods, the proportion was often assumed equal for simplicity $(\mathrm{a}=0.5)$.

VHI range from 0 to 100 with next five drought classes: extreme drought (0-10), severe drought (10-20), moderate dought (20-30), mid drought (30-40), no drought (40-100).

\section{RESLUTS AND DISCUSSION}

Figure 1 shows LST, NDVI, VSWI, NVSWI, VCI, TCI and VHI maps and table 1 shows statistical data of LST and NDVI. On may 4th the maximum value of temperature was about $35^{\circ} \mathrm{C}$ and on june $5^{\text {th }}$ the parameter mean of temperature was over $26^{\circ} \mathrm{C}$. Analizying the parameter "mean" of NDVI we notice it grew from 0.51 to 0.6 between 04.05.2017 and 05.06.2017, that fact indicate an increase for vegetation coverage of the land. 

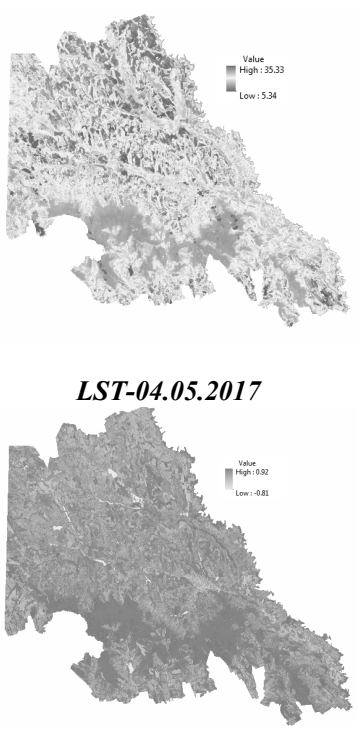

NDVI-05.06.2017

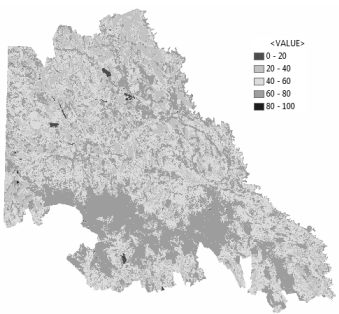

NVSWI-04.05.2017

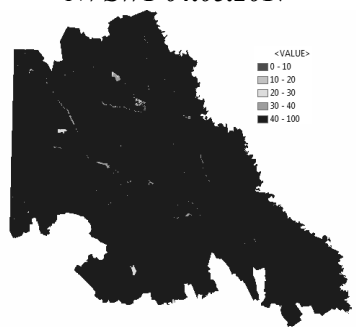

VCI-05.06.2017

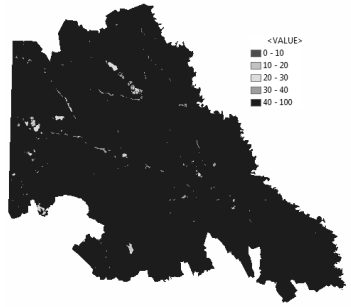

VHI-04.05.2017

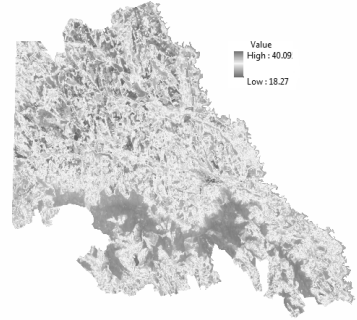

LST-05.06.2017

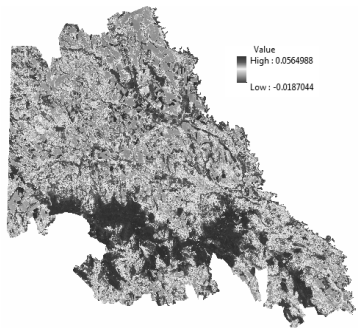

VSWI-04.05.2017

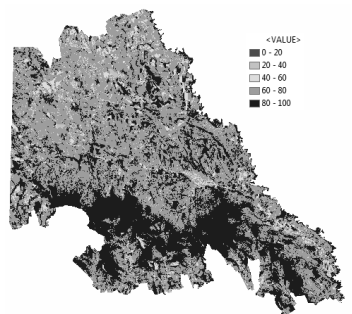

NVSWI-05.06.2017

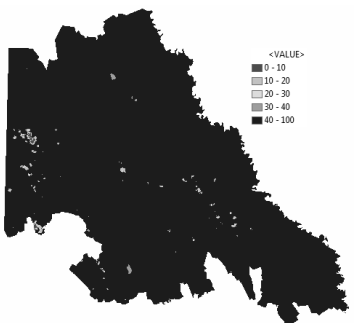

TCI-04.05.2017

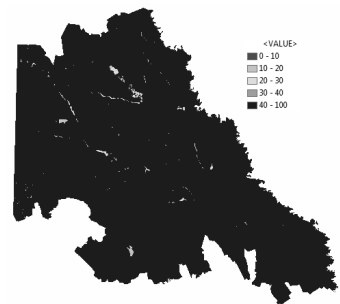

VHI-05.06.2017

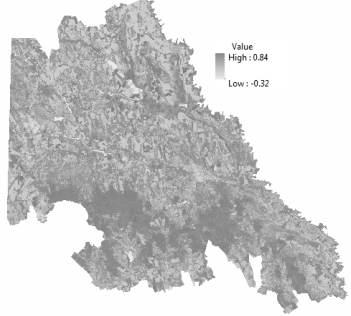

NDVI-04.05.2017

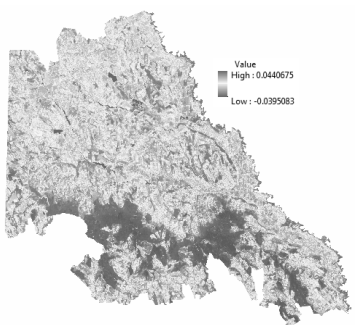

VSWI-05.06.2017

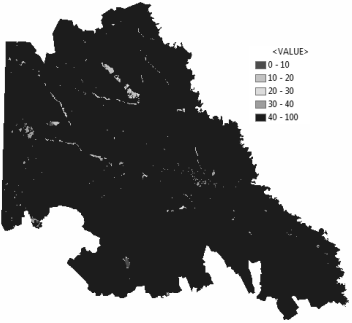

VCI-04.05.2017

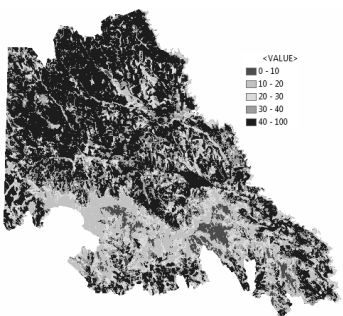

TCI-05.06.2017

Fig. 1. LST, NDVI, VSWI, NVSWI, VCI, TCI, VHI maps 
After applying NVSWI to determine the degree of drought, it was noticed that for the satellite image of May prevailed "slight drought" and for june "normal". Second index, VHI indicates that in both months, may and june, is "no drought".

Table1. Statistics data

\begin{tabular}{|c|c|c|c|c|}
\hline Parameter & Date & Minimum & Maximum & Mean \\
\hline \multirow{2}{*}{ LST } & 04.05 .2017 & 5.34 & 35.33 & 24.47 \\
\cline { 2 - 5 } & 05.06 .2017 & 18.28 & 40.1 & 26.6 \\
\hline \multirow{2}{*}{ NDVI } & 04.05 .2017 & -0.33 & 0.84 & 0.51 \\
\cline { 2 - 5 } & 05.06 .2017 & -0.82 & 0.92 & 0.60 \\
\hline
\end{tabular}

\section{CONCLUSIONS}

In this paper drought was evaluated, for Iasi county, using NVSWI and VHI. We discovered that both indicies can be successfully used to determine the spatiotemporal extent of agricultural drought. After applying NVSWI to determine the degree of drought, it was noticed that for the satellite image of May prevailed "slight drought" and for june "normal". Second index, VHI indicates that in both months, may and june, is "no drought". It can be concluded that Vegetation Health Index is very good indicator for studing extreme drought and Normalized Vegetation Supply Water Index offer information about areas "normal" and "wet".

\section{REFERENCES}

1. Barsi, J.A., Schott, J.R., Hook, S.J., Raqueno, N.G., Markham, B.L., Radocinski, R.G. (2014), Landsat-8 thermal infrared sensor (TIRS) vicarious radiometric calibration, 6(11), 11607-11626.

2. Bryant, H.R., Wilhite D.A. (1999), Objective quantification of drought severity and duration, J Climate 12, 2747-2756.

3. Chander, G., Markham, B.L., Helder, D.L. (2009), Summary of current radiometric calibration coefficients for Landsat MSS, TM, ETM+, and EO-1 ALI sensors, Remote Sensing of Environment 113(5), 893-903.

4. Coll, M., Piroddi, C., Steenbeek, J., Kaschner, K., Ben Rais Lasram, F., Aguzzi, J., et al. (2010), The Biodiversity of the Mediterranean Sea: Estimates, Patterns, and Threats. PLoS ONE5(8), e11842.

5. Heim, R.R. (2002), Jr. A review of twentieth-century drought indices used in the United States. Bull. Am. Meteorol. Soc., 83, 1149-1165.

6. Hirche, A., Salamani, M., Abdellaoui, A., Benhouhou, S.,Valderrama, J. M. (2011), Landscape Changes of Desertification in Arid Areas: The Case of SouthWest Algeria, Remote Sens., 179 (1-4), 403-420.

7. Jentsch, A., Kreyling, J., Beierkuhnlein, C. (2007), A new generation of climate change experiments: events, not trends. Front Ecol Environ 5, 365-374.

8. Jiménez-Muñoz, J.C., Sobrino, J.A., Skokovic, D., Mattar, C., Cristóbal, J. (2014), Land Surface Temperature (LST) Retrieval Methods From Landsat-8 Thermal 
Infrared Sensor Data, IEEE GEOSCIENCE AND REM. SENS. LETTERS, VOL. $11(10)$

9. Knapp, A.K., Beier, C., Briske, D.D., Classen, A.T., Luo, Y, Reichstein, M., Smith, M.D., Smith, S.D., Bell, J.E., Fay, P.A., Heisler, J.L., Leavitt, S.W., Sherry, R., Smith, B., Weng, E. (2008), Consequences of more extreme precipitation regimes for terrestrial ecosystems, Bioscience 58:811-21.

10. Knutson (1998), Methods and Tools for Drought Analysis and Management, Trans. Am. Geophysical Union.

11. Kogan, F. N., Vargas, M., Ding, H., Guo, W. (2011), VHP Algorithm Theoretical Basis Document, NOAA NESDIS CENTER FOR SATELLITE APPLICATIONS AND RESEARCH

12. Kogan, F. N. (1995), Application of vegetation index and brightness temperature (BT) for drought detection. Advances in Space Research, 15, 91-100.

13. Min, S., Zhang, X., Zwiers, F.W., Hegerl, G.C. (2011), Human contribution to more-intense precipitation extremes. Nature 470:378-81.

14. Nagarajan, R., Mahapatra, S. (2003), Land Based Information System for Drought Analysis, CSDMS, 11-13.

15. Pandey, P.C., Rani, M., Srivastava, P.K., Sharma, L.K, Nathawat, M.S. (2013), Land Degradation Severity Assessment with Sand Encroachment in an Ecologically Fragile Arid Environment. A Geospatial Perspective, Qscience Connect 2013, 43.

16. Reichstein, M., Bahn, M., Ciais, P., Frank, D., Mahecha, M.D., Seneviratne, S.I., Zscheischler, J., Beer, C., Buchmann, N., Frank, D.C., Papale, D., Rammig, A., Smith, P., Thonicke, K., Van der Velde, M., Vicca, S., Walz, A., Wattenbach, M. (2013), Climate extremes and the carbon cycle, Nature 500, 287-95.

17. Rouse, J.W., Haas, R.H., Schell, J.A. (1974), Monitoring the vernal advancement and retrogradation (greenwave effect) of natural vegetation, Texas $\mathrm{A}$ and $\mathrm{M}$ University, College Station.

18. Smith, M.D. (2011), An ecological perspective on extreme climatic events: a synthetic definition and framework to guide future research, J Ecol 99, 656-663

19. UNDP (2008), available on-line at: http://hdr.undp.org

20. Wilhite, D.A. (2000), Drought Planning and State Government: Current Status, Bul. Am. Met. Soc.

21. Zhang, A., Jia, G., (2013), Monitoring meteorological drought in semiarid regions using multi-sensor microwave remote sensing data, Remo. Sens. Environ., 134, $12-23$.

22. $* * *$ miningeology.blogspot

23. *** NASA Landsat Science 